\title{
Asynchronous software systems projected to support teaching and learning in Higher Education
}

\author{
M. Travassos Valdez ${ }^{1}$, C. Machado Ferreira ${ }^{1}$, Maria João M. Martins ${ }^{2}$, F. P. Maciel Barbosa ${ }^{3}$ \\ ${ }^{1}$ Instituto Superior de Engenharia de Coimbra, Instituto Politécnico de Coimbra, \\ Coimbra, Portugal \\ ${ }^{I}$ valdez@isec.pt; cmacfer@isec.pt \\ ${ }^{2}$ Academia Militar, DCTE \& INESC-ID \\ Lisboa, Portugal \\ ${ }^{2}$ mariajoaomartins2@gmail.com \\ ${ }^{3}$ Faculdade de Engenharia, Universidade do Porto \& INESC TEC \\ Porto, Portugal \\ ${ }^{3}$ fmb a fe.up.pt
}

\begin{abstract}
Virtual labs are more likely to offer a user friendly environment as well as greater flexibility, allowing students to carry out experiments and repeat them as often as necessary. Nevertheless, they do not discard the need for a conventional system as traditional labs are a valuable asset. In this context, the student is the centre of the whole process, taking on the main role and is responsible for his/her own learning process, although there may be an extra support through in-class sessions in order to keep him/her in contact with the system, to offer guidance and motivation for the challenges ahead.

One of the advantages of virtual experimentation is the opportunity of using a lab in situations which might be impossible otherwise, allowing students to take part in lab sessions; another one is related with its use to improve learning results. Virtual experimentation labs create flexible learning environments suitable for different types of learners, allowing the interactive and systematic development of competences in the various areas of learning and can be used to complement the conventional type of lectures.

VEMA is a practical asynchronous software tool devised to meet the needs of students who can't be present in regular lab classes in the Electrical Engineering Department of ISEC (Instituto Superior de Engenharia de Coimbra).
\end{abstract}

Keywords - E-learning, interactive application, software packages, virtual reality, 3D lab internet

\section{INTRODUCTION}

Information and communication technologies have brought about numerous changes in the life of universities, which are happening quite fast. Teaching and learning are not isolated activities and are regarded as a cooperative effort of all those involved in the process. Teaching and learning are no longer restricted to the work developed inside the classrooms and distance as well as classroom teaching is beginning to be challenged, defying higher education institutions (HEI) to find new models for new situations. One of the most important tasks of HEI is to create more flexible curricula and the most challenging one is the integration of in-class activities with distance learning (DL).
To face all these new challenges, education institutions, and in special higher education institutions are creating Life-Long Learning (LLL) programs, enabling the general public and all students to enrol in their course studies to update their knowledge. These projects resort to technology, specially computing networks, with a special focus on the internet [1-2]. The learning environments created to assist these programs are explored by teachers with the objective of developing pedagogical work according to modern theories of education, with special emphasis on participation, interaction and development of creativity.

This paper suggests the use of virtual experimentation as support to teaching/learning environments, considering that it can support the existing educational models [3]. Virtual experimentation labs present a simulated reality, similar to hands-on labs requiring space and tools, but different from them because the experiments and users are geographically apart [4-5]. A virtual experimentation lab can put learners in contact with life-like situations since the lab activities are seen to have a major role in the preparation of learners, mainly in areas of natural and technological sciences, represent a way to share resources and reduce costs, and it is considered to be a source of educational improvement.

\section{Distance LEARNING}

An educational environment requires access to materials at school, at home, in books and online to foster the acquisition of competences. In order to enhance motivation, non-formal digital practices should be more frequent in the classroom as well as in adult education.

Access to learning opportunities is mandatory, with adequate rhythm and duration, at convenient times and places, using computer technologies associated with life or work, as individualized preparation at beginner level or as lifelong learning. Distance Learning (DL) or the use of computer technologies has proved to be efficient as technology and 
computing allow an ample access to knowledge. Besides, computer technologies can make learning more efficient, providing access to competences and knowledge, difficult to get otherwise.

Education institutions and schools must be prepared for changes in their roles in order to ensure quality education. Teachers should be critical thinkers, problem solvers, good communicators and collaborators, with some knowledge of information technology, flexible and adaptable, innovative and creative and environmentally literate. A new model of education is needed to develop these skills and abilities in the students. To provide educational innovation it is necessary to use new technologies.

There are courses already combining theory with virtual experiments [6-8]. Virtual and remote labs open up new insights by broadening the spectrum of experimentation [7]. They have become a new pedagogical resource which, combined with others, can be integrated into e-learning teaching platforms. Virtual Reality (VR) teaches complex, expensive or dangerous systems inexpensively, by using a computer screen and allows the examination and manipulation of computer generated tridimensional interactive environments, in real time. VR systems are considered quite adequate for visual and spatial recreation of real environments.

The feature which most stimulated the interest in using Distance Learning was the fast and easy way of promoting the teacher/student interaction, which can be achieved by using a variety of methods and techniques, with synchronous and asynchronous approaches.

Distance Learning (DL) may be described as a method which does not require teachers and students to meet at a certain day or time. Virtual reality environments open up new perspectives to group cooperation by allowing students to interact with a real life or imaginary world through simulations, or through the manipulation of virtual objects in the real world.

The last DL generation is made of virtual communities with easy to use, quite interactive and accessible e-learning systems. The student may be at home or in the workplace with no interaction with the rest of the participants, teacher or other students.

The system is considered synchronous when the participants need to be simultaneously in contact with environment in order to facilitate the cooperation. When simultaneity is not an issue the system is considered asynchronous.

Each learner is unique, with a very specific rhythm, so he/she can be considered passive or reactive. [9].

Students may have different characteristics, so it is necessary to admit that they have different aptitudes, capacities and qualities. Therefore, it is logical to believe that each individual will need a different time span to use or perform the learning activities. There may also be different learning rhythms, in terms of acquisition of information as well as progression.

By studying the learning styles, a diagnostic tool can be perfected in order to characterize lifelong learning so that one can understand how a certain student handles or deals with experimentation, reflects, induces hypothesis and manages to apply that formula in real life. This is why the development of Educational Software (ES) should resort to interactivity, using the stimuli in order to facilitate an easy way to perceive information and thus reducing the learning pace.

As a pragmatic learner, the user/student utilizes, applies and/or learns by resorting to practice, as in games or repetitive exercises, tests or simulations.

In the present case, a measures and instrumentation lab representation was created - ES (educational software) in which the user will perform the role of the student in that very same lab. An evaluation is always necessary, i.e. as the action unfolds, there has to be some form of dialogue between the student/user and the ES.

The ES allows the user to assume control of the learning pace, within well-defined parameters, providing motivation free from anxiety. The interaction may be frequent and diversified, using some form of relevant animation or charts/graphs.

\section{VIRTUAL REALITY - MODEL OF INNOVATION PROTOTYPE}

The technologies used in a DL model should concentrate on the interface elements as incentive to use communication as teaching methodology. [10-11].

When creating scenes, the requirements of rendering in Virtual Reality (VR) are in general greater than when representing Augmented Reality (AR). In VR the images replicate the real world and all virtual objects have to be rendered with great precision (see fig 1 and fig. 2).

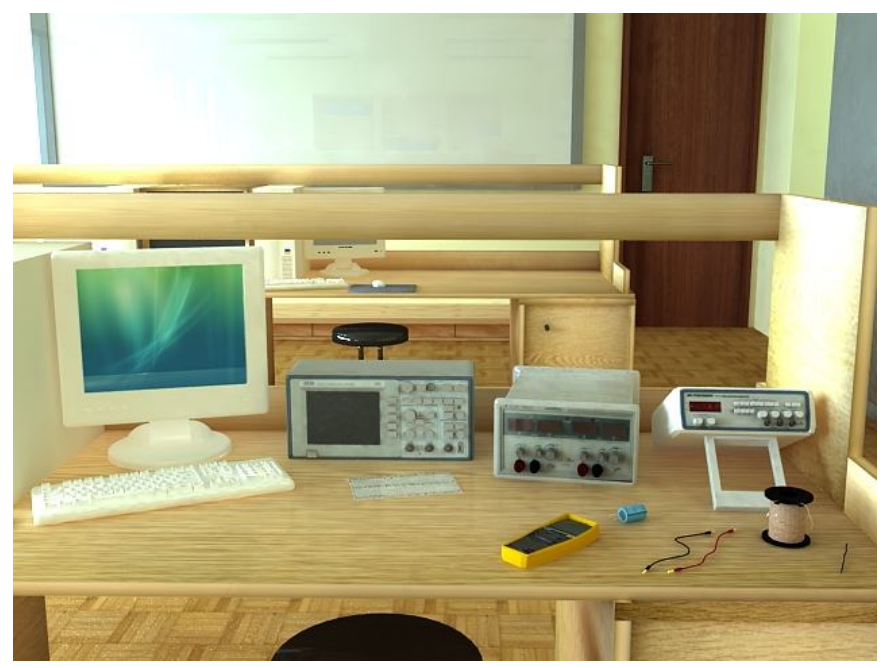

Fig.1 Rendering of a virtual lab environment in VEMA

With AR the images are used to complement the real world and the virtual objects aren't always rendered with absolute realism. In terms of visualization, AR visualization devices may be quite demanding. AR has more strict specifications than VR (related with alignment problems), as it needs to follow and track information about the environment with varying levels of accuracy and precision.

The use of VR labs definitely contributes to the learning process, enhancing the possibilities of course and curricular unit development and more up-to-date pedagogy. 

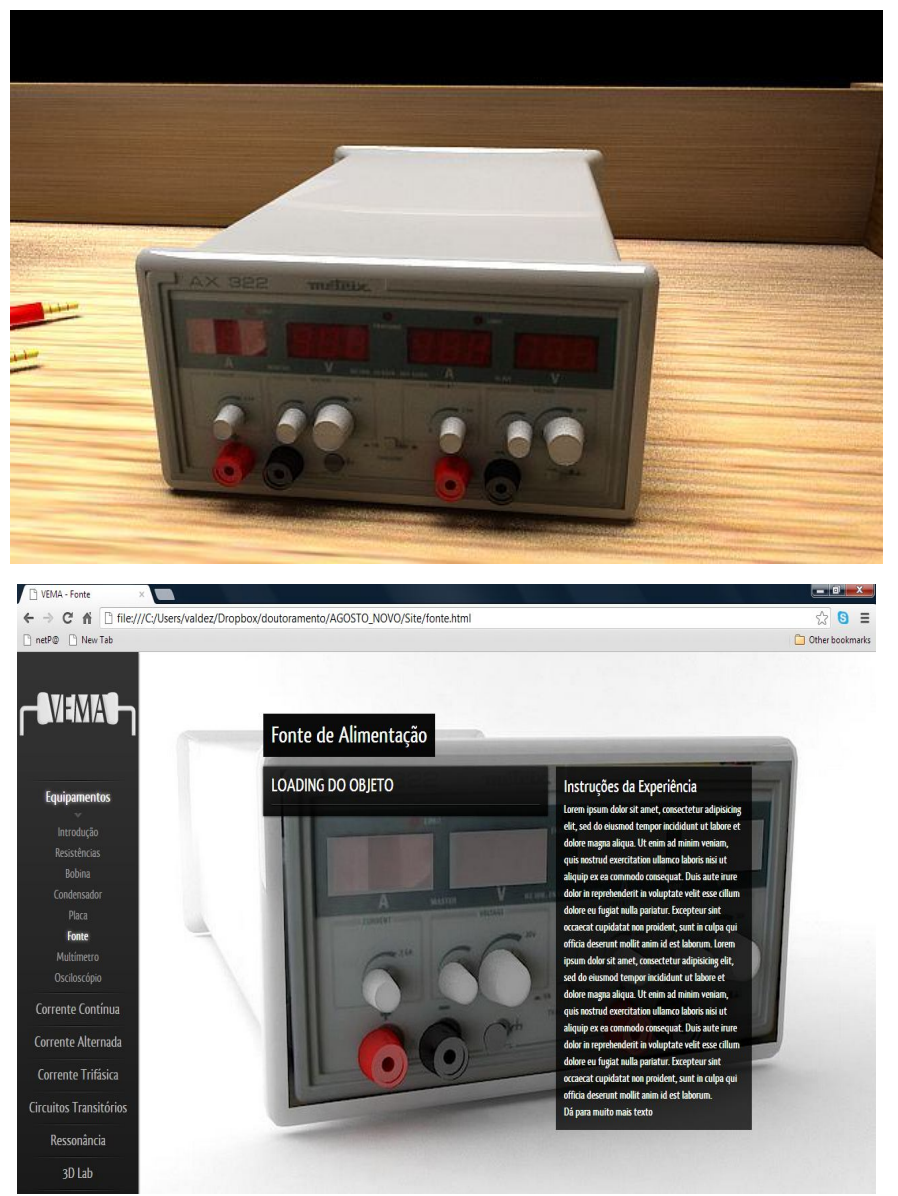

Fig.2 Rendering of a Power supply in VEMA

\section{VIRTUAL REALITY - SYNCHRONOUS AND ASYNCHRONOUS COOPERATIVE SYSTEMS}

The characteristic which most stimulated the use of DL was the swift and easy interaction between teacher/student. The mediation of this interaction can be achieved using various synchronous and asynchronous techniques and approaches.

Synchronous technologies use real time communications, in spite of all the disadvantages in terms of costs and infrastructures. They are more complicated and costly, for the students as well as for the institution; therefore, less common. Nevertheless, because they allow a synchronous and interactive communication, they have the potential of recreating the traditional teaching. Its use may become more limited not only in terms of technology, but also because it requires compatible schedules.

Asynchronous internet technology is widely used by most institutions that offer courses primarily based on DL. As there is no need for the simultaneous presence of students and teacher, the interaction between them becomes more flexible since it may be performed at different times, also providing access to teaching materials at any time and any place, facilitating global accessibility and reducing costs.
Virtual labs can be used as an alternative to the conventional models. Experiments with simulated models are comparable, provided that they comply with the principles and use of mathematical models that represent the important details of the system in analysis and with animations that allow the student to visualize and understand how to use a lab.

A computer tool was developed (VEMA-"Virtual Electric Manual") and designed to provide an integrated system for the implementation of an interactive virtual lab. The final product is an application in a system supervisor also inherent in the learning object (see fig.3) [12].

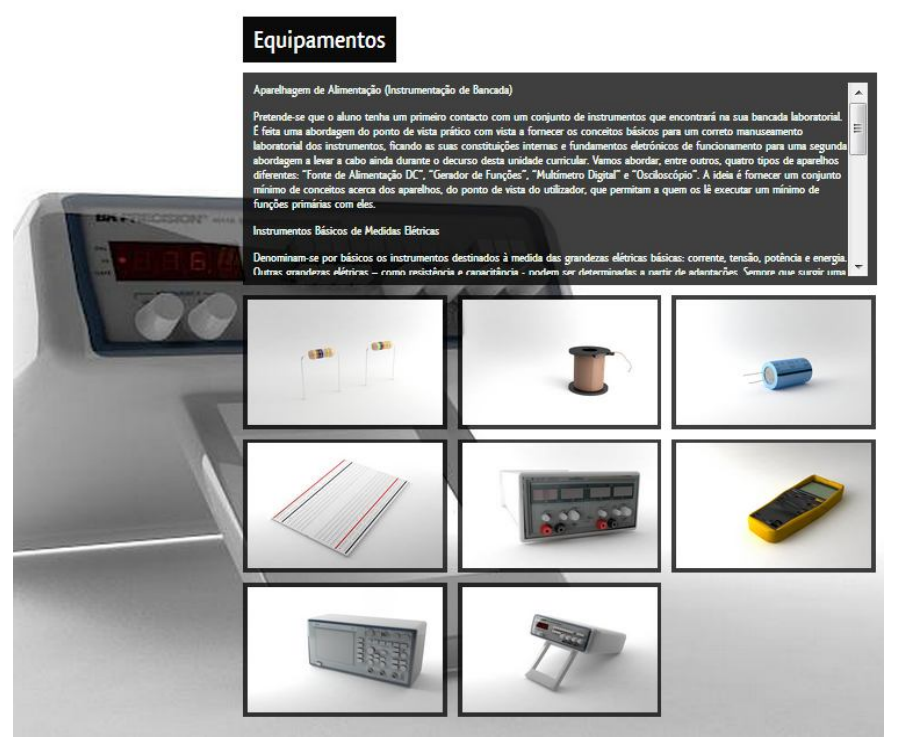

Fig.3 VEMA equipment menu

There is a better dynamic for the performance of the students as, in this case, students can send doubts or questions to the teacher at a given moment and the teacher can answer them in due time, without worrying about the end of the lecture/session (see fig.4). It also stimulates students to better consider the contents of their questions [8]. In such cases learning may take on the form of an active, interactive and descriptive experimentation.
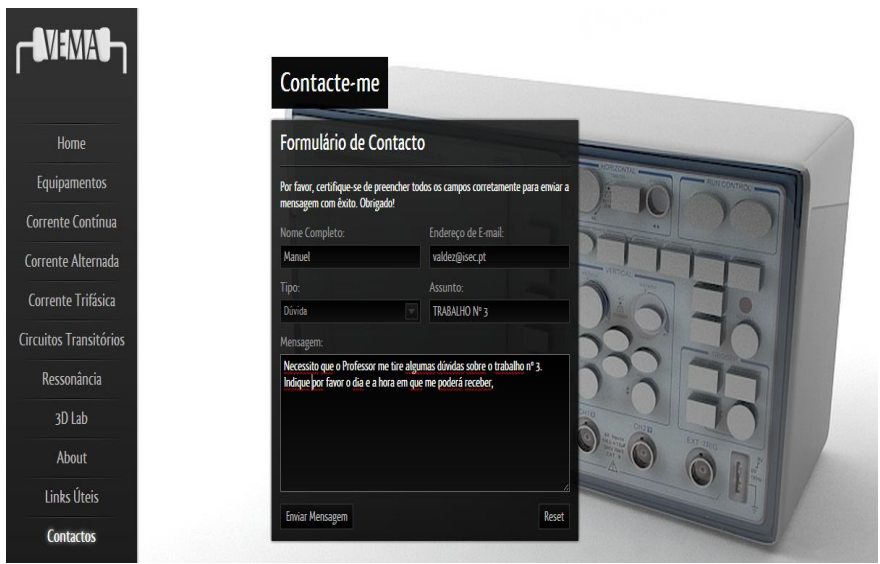

Fig. 4 VEMA, contact menus 


\section{CONCLUSION}

There is often a gap between theory and practice in education. Teachers tend to consider their practice through educational theories; on the other hand, students do not have enough practice-oriented experiences.

Although the teachers' main role is to teach students, in order to apply an innovative and successful format of students' education it is necessary to combine their traditional roles with their new roles as educators.

It is expected that all students should have practice in schools. This can easily be met because of the new format of an innovation prototype. It is possible to increase the quality of practice-oriented teaching at the university by engaging students. Their involvement is not very easy, but it can be improved with more flexibility, giving them more time to practice along the course, combining their knowledge and skills.

Learning by doing is a basic element in modern education. The added value granted by the means of communication and the infinite possibilities of treating information using very powerful computer programs may certainly bring true and meaningful benefits to the learning process.

The model of innovation prototype VEMA has been developed based on research and practice. The dimension of collaboration has been specified as traineeship, professional development, team work, research and development [12].

In this model, the teacher is involved in observing and supervising student work throughout a school year, using a positive attitude toward improving students' competences. The pedagogical traineeship should provide students with an opportunity to perform observation tasks with a variety of electric circuit elements.

VEMA was planned to apply all the resources that can be used in lab training, so that students can use a significant amount of their working time on experimental work.

VEMA is a flexible educational prototype where it is possible to adapt learning contents and management in cooperation with a student's needs. The main objective was to explore the sharing of resources of a Measurements and Instrumentation laboratory, both increasing the expected number of participants and extending its time span and good use, as the experiments in the model are performed in a virtual way, making it possible to rationalize its use and costs [13]. As it is an open system, as far as Circuit Theory is concerned, the model allows the addition of new experiments, as they will be made available, or the update of the ones already used.

New technologies may well be added not only to amplify the resources of experiments already implemented, but also to include new ones.

With this approach students may more easily perform practical lab experiments and, at the same time, the organization and time management is broadened when compared with conventional practical sessions in class.

Very rich exercises can be undertaken in virtual worlds and experimental learning in these contexts holds exciting scenarios for the educational field.
Students must ultimately practice in a way that engages them to promote a change, the practice of skills, the construction of knowledge and not just assimilating facts.

Virtual learning does not seek the accumulation of facts so much as the construction of new meanings.

Virtual worlds provide almost unlimited opportunities to test and practice behaviours in a safe environment.

\section{ACKNOWLEDGMENT}

The authors wish to acknowledge, The European Commission through the SALEIE project (Strategic Alignment of Electrical and Information Engineering in European Higher Education Institutions) for grants and support, and thank the SALEIE project partners for fruitful discussions on the subject of Life-Long Learning.

\section{REFERENCES}

[1] Papert, S., "What's the big idea? steps toward a pedagogy of idea power", IBM Systems Journal, 2000.

Available in: http://www.oppapers.com/essays/Outdoor-Learning/ 609432.

[2] Patera, M., "The Potencial of 3D Visualisation Technology in Art and Design Education". Doctor Thesis submitted for the Glasgow School of Art/University of Glasgow, May, 2009.

[3] M. Sauter, D. H. Uttal, D. N. Rapp, M. Downing, and K. Jona, "Getting real : the authenticity of remote labs and simulations for science learning," Distance Education, vol. 34, no. 1, pp. 37-47, 2013.

[4] J. Maitem, R. J. Cabauatan, L. Rabago, B. Tanguilig, "Math World: A Game-Based 3d Virtual Learning Environment (3d Vle) For Second Graders", The International Journal of Multimedia \& Its Applications (IJMA) Vol.4, no.1, February 2012.

[5] J. E. Corter, S. K. Esche, C. Chassapis, J. Ma, and J. V. Nickerson, "Process and learning outcomes from remotely-operated, simulated, and hands-on student laboratories," Computers \& Education, vol. 57, no. 3 , pp. 2054-2067, Nov. 2011.

[6] J. L. Thames, R. Abler, A. Hyder, R. Wellman, and D. Schaefer, "Architectures and Design Methodologies for Scalable and Sustainable Remote Laboratory Infrastructures," in in Internet Accessible Remote Laboratories: Scalable E-Learning Tools for Engineering and Science Disciplines, PA, USA: IGI Global, pp. 254-275, 2012.

[7] C. Salzmann and D. Gillet, "Smart device paradigm, Standardization for online labs," Global Engineering Education Conference (EDUCON), IEEE, Berlin, pp. 5, 2013.

[8] S. Seiler, "Laboratory as a Service A Holistic Framework for Remote and Virtual Labs," Doctoral Thesis Doctoral thesis in management, Faculty of Mechanical Engineering-Department of Mechatronics, Tallinn University of Technology, 2012.

[9] Fosnot, Catherine Twomey. "Construtivismo: uma teoria Psicológica da Aprendizagem",. In: Construtivismo: teoria, perspetivas e prática pedagógica. Tradução Sandra Costa. Porto Alegre: Artes Médicas. Capítulo 2, 1998. (in portuguese)

[10] Chen, Y., "A study of comparing the use of augmented reality and physical models in chemistry education". In: Vrcia '06: Proceedings of the 2006acm international conference on virtual (2006).

[11] Kissel, A., "Distance Education: Engineering the Pedagogy", UMUC, SWEN603.

[12] M. Travassos Valdez, C. Machado Ferreira and F. P. Maciel Barbosa, "Virtual Reality Prototype as a Tool in a Lab Environment". PRAXIS 2012, PRAXIS'12 The Open Discussion Forum. Wroclaw University of Technology. Poland. 6-7 September 2012.

[13] Tori, R., "Educação sem distância: as tecnologias interativas na redução de distâncias em ensino e aprendizagem". São Paulo: Editora SENAC. 2010. (in portuguese) S. M. Metev and V. P. Veiko, Laser Assisted Microtechnology, 2nd ed., R. M. Osgood, Jr., Ed. Berlin, Germany: Springer-Verlag, 1998. 